\title{
Isolation and characterization of a novel podovirus which infects burkholderia pseudomallei
}

\author{
Jiraporn Gatedee ${ }^{1}$, Kanyanan Kritsiriwuthinan², Edouard E Galyov³ ${ }^{3}$ Jinyu Shan ${ }^{3}$, Elena Dubinina ${ }^{3}$, Narin Intarak ${ }^{1}$, \\ Martha RJ Clokie $^{3}$ and Sunee Korbsrisate ${ }^{1^{*}}$
}

\begin{abstract}
Burkholderia pseudomallei is a saprophytic soil bacterium and the etiological agent that causes melioidosis. It is naturally resistant to many antibiotics and therefore is difficult to treat. Bacteriophages may provide an alternative source of treatment. We have isolated and characterised the bacteriophage ФBP-AMP1. The phage is a member of the Podoviridae family and has a genome size of $\sim 45 \mathrm{~Kb}$. Molecular data based on the gene which encodes for the phage tail tubular protein suggests that the phage is distinct from known phages but related to phages which infect B. thailandensis and Ralstonia spp. The phage $\Phi B p-A M P 1$ is the first B. pseudomallei podovirus to be isolated from the environment rather than being induced from a bacterial culture. It has a broad host range within $B$. pseudomallei and can infect all 11 strains that we tested it on but not related Burkholderia species. It is heat stable for $8 \mathrm{~h}$ at $50^{\circ} \mathrm{C}$ but not stable at $60^{\circ} \mathrm{C}$. It may potentially be a useful tool to treat or diagnose B. pseudomallei infections as it can lyse several strains of clinical relevance.
\end{abstract}

Keywords: Burkholderia pseudomallei, bacteriophage, Podoviridae

\section{Findings}

Burkholderia pseudomallei is a Gram-negative bacillus and the causative agent of melioidosis which is endemic in Southeast Asia and northern Australia [1]. The bacterium is a widely distributed environmental saprophyte commonly found in water and soil in the endemic areas. The bacterium is highly resilient to environmental stress and can survive in distilled water for months or even years [2]. It infects humans via inoculation through skin abrasions or via the inhalation route and causes either acute or chronic melioidosis. Acute infection is often manifested as septicemia, resulting in death within days of exposure. B. pseudomallei is resistant to many antibiotics including third-generation cephalosporins [3]. There is clearly a need for novel antimicrobials. One promising source of antimicrobials may come from bacteriophages which infect and kill specific bacterial cells. They are the most abundant living entities in the world, and play key roles in bacterial population dynamics and evolution [4]. Bacteriophages can be either temperate

\footnotetext{
* Correspondence: grsks@mahidol.ac.th

'Department of Immunology, Faculty of Medicine Siriraj Hospital, Mahidol University, Bangkok 10700, Thailand

Full list of author information is available at the end of the article
}

where they integrate into the host bacterial genomes, or virulent where they infect, multiply, and lyse their hosts without any initial integration period. The ability of such virulent phages to be used therapeutically has been well documented and reviewed [5,6].

Prophages have been shown to be abundant in $B$. pseudomallei genomes [7-9]. A recent study reported the abundance and diversity of prophages in B. pseudomallei, $B$. thailandensis and B. mallei genomes and suggested how they contribute to the phenotypic diversity in the Burkholderia species complex [8]. Pertinently to our study, the 37 phages identified in the Burkholderia genomes were either myoviruses, $\mathrm{Mu}$-like viruses, or siphoviruses. Although one previous study reported the presence of a putative podovirus in the genome of $B$. pseudomallei, there are no published genetic studies to support this work [7]. Another recent study isolated six B. pseudomallei myoviruses from soil in Thailand, these were morphologically characterised to have lytic properties [10].

We report the isolation of a podovirus which is specific to B. pseudomallei. To isolate the phage, one hundred and fifty soil samples were screened. The samples were collected from rice fields within the Khon Kaen
C Biomed Central

() 2011 Gatedee et al; licensee BioMed Central Ltd. This is an Open Access article distributed under the terms of the Creative Commons Attribution License (http://creativecommons.org/licenses/by/2.0), which permits unrestricted use, distribution, and reproduction in any medium, provided the original work is properly cited. 
Province, Thailand. The soil samples were collected during the rainy season from a depth of around 10-20 cm. The ambient temperature in rice fields varies with season ranged from $23-35^{\circ} \mathrm{C}$ and in the summer time temperatures reach $40-45^{\circ} \mathrm{C}$. Two grams of each soil sample was placed into $10 \mathrm{ml}$ Luria-Bertani (LB) broth supplemented with $0.5 \mathrm{mM} \mathrm{CaCl}_{2}$. Each sample was mixed thoroughly, incubated at room temperature overnight, centrifuged at $4000 \times \mathrm{g}$ for $20 \mathrm{~min}$ and then passed through a $0.22 \mu \mathrm{m}$ filter. Ten microlitre volumes were used in spot assays on B. pseudomallei strain K96243 grown on LB agar supplemented with $0.5 \mathrm{mM} \mathrm{CaCl}_{2}$. The phage was purified and kept as stock in SM-buffer with $50 \%$ glycerol at $-70^{\circ} \mathrm{C}$.

The isolated phage was designated Bp-AMP1 and characterised using transmission electron microscopy (TEM). This analysis revealed that it belongs to the podovirus family as it has an icosahedral capsid with a diameter of $\sim 45 \mathrm{~nm}$ and a characteristically small podovirus tail of $\sim 20 \mathrm{~nm}$ tail (Figure 1A). Pulsed field gel electrophoresis (PFGE) was carried out as described previously [11]. This revealed that the genome size was consistent with a typical podovirus size of approximately $45 \mathrm{~Kb}$ (Figure 1B). Phage DNA was digested using the restriction enzyme $B s t \mathrm{BI}$ and a discrete DNA banding pattern was obtained (Figure $1 \mathrm{C}$ ). The total size of the restriction fragments from this digestion amounted to $45.5 \mathrm{~Kb}$ and correlates with the PFGE estimate.

To investigate the host range of $\Phi B \mathrm{P}-\mathrm{AMP} 1$, plaque assays were performed on $10 \mathrm{~B}$. pseudomallei strains isolated from distinct geographic locations, 6 B. thailandensis strains, 4 other Burkholderia spp., Pseudomonas aeruginosa and Escherichia coli strains (Table 1).

ФBp-AMP1 could infect all 11 B. pseudomallei strains however in general they were more efficient at infecting the Thai $B$. pseudomallei strains than the Australian strains. To do these efficiency assays, a known amount of phage stock derived from being propagated on K96243 was added to each host strain tested. This stock gave a titre of $2.90 \times 10^{7} \mathrm{pfu} / \mathrm{ml}$ when grown on the host strain. However, the titre was much lower on the Australian strains with the least good host being MSHR668 which only had a titre of $10 \pm 1.66 \mathrm{pfu} / \mathrm{ml}$. There are some exceptions to this and the Thai strain E8 was not an efficient host for the phage. It could not infect any of the tested 6 strains of $B$. thailandensis or the B. multivorans, $B$. ubonensis, B. cepacia, B. vietnamiensis, P. aeruginosa and $E$. coli. To the best of our knowledge, this is the first isolation of a Podoviridae family bacteriophage which specifically infects $B$. pseudomallei. Although $B$. pseudomallei myoviruses have been isolated previously, because myoviruses generally do not share any genes in common with podoviruses, $\Phi B \mathrm{~B}$-AMP1 is likely to

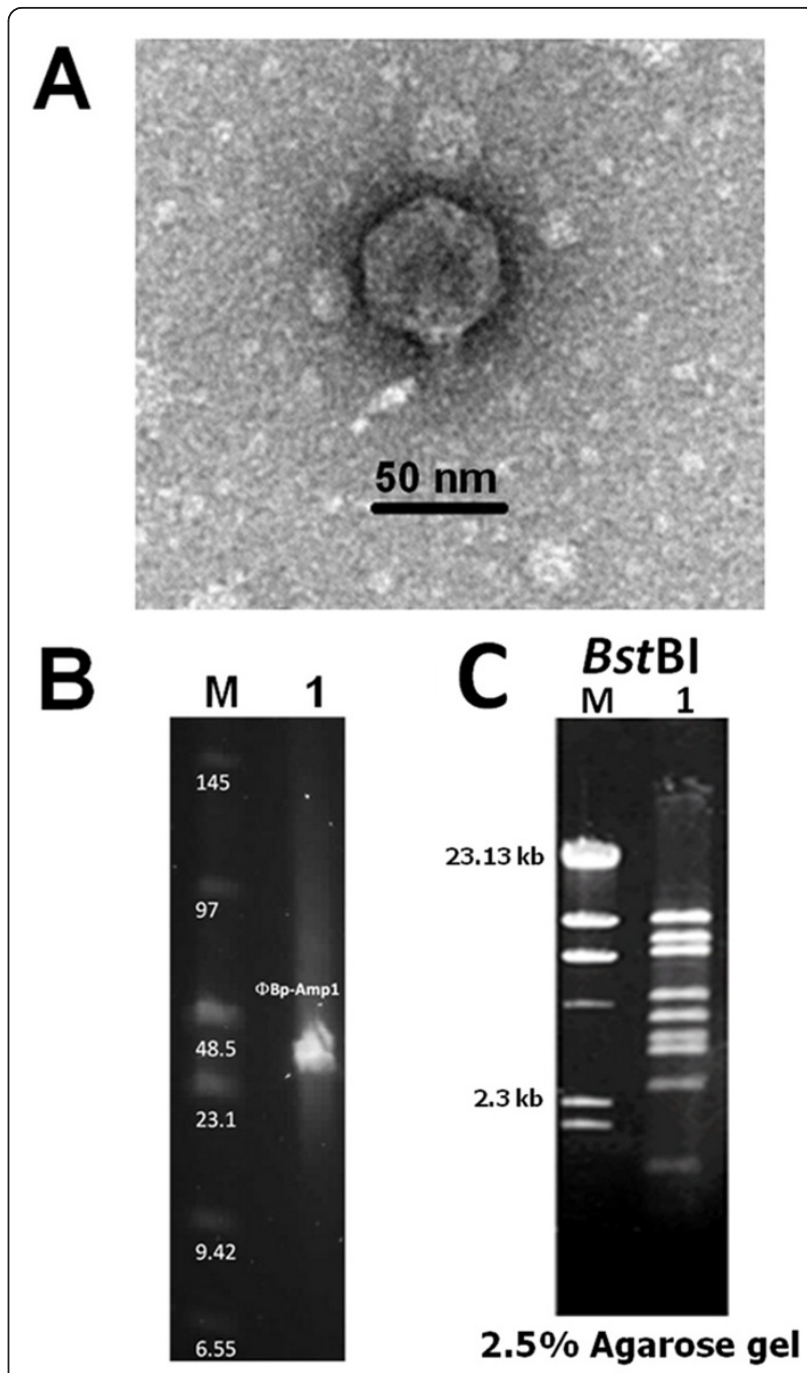

Figure 1 Electron microscopic and DNA analysis of ФBp-AMP1. (A) Transmission electron micrograph and ФBP-AMP1 (B) The genome size of $\Phi B p-A M P 1$ determined by PFGE. (C) Restriction DNA pattern of ФBp-AMP1 genomic DNA digested with BstBI (lane1). Lane $M, \lambda$ Hind III DNA marker.

have a novel set of antimicrobial properties to those found in B. pseudomallei myoviruses.

In order to characterise the physiological characteristics of this phage, one-step growth curve experiments were performed as previously described [12]. Briefly, cultures of B. pseudomallei K96243 with ca. $1 \times 10^{8}$ bacteria were resuspended in $1 \mathrm{ml} \mathrm{LB}$ medium and incubated with $\Phi B \mathrm{~B}-\mathrm{AMP} 1$ at a multiplicity of infection (MOI) 0.1 . The mixture was incubated at $37^{\circ} \mathrm{C}$ for 10 min before centrifugation and resuspension in $10 \mathrm{ml}$ of pre-warmed LB broth supplemented with $0.5 \mathrm{mM} \mathrm{CaCl}_{2}$ and incubated at $37^{\circ} \mathrm{C}$. Five hundred microlitres of culture was taken at 20 min intervals over a period of $3 \mathrm{~h}$ and the number of phage particles was immediately 
Table 1 Efficiency of $\Phi$ Bp-AMP1 to form plaques on 10 B. pseudomallei and on other bacterial strains.

\begin{tabular}{|c|c|c|c|}
\hline Bacteria & Strain & Source and location & Titres (pfu/ml) \\
\hline \multirow[t]{10}{*}{ B. pseudomallei } & $3073 \mathrm{~A}$ & Clinical isolation, Thailand & $(3.00 \pm 0.41) \times 10^{7}$ \\
\hline & 576 & Clinical isolation, Thailand & $(2.70 \pm 0.37) \times 10^{7}$ \\
\hline & $1710 a$ & Clinical isolation, Thailand & $(1.50 \pm 0.15) \times 10^{6}$ \\
\hline & BA18 & Clinical isolation, Australia & $(3.10 \pm 0.33) \times 10^{5}$ \\
\hline & MSHR42 & Clinical isolation, Australia & $(4.00 \pm 0.44) \times 10^{5}$ \\
\hline & MSHR287 & Clinical isolation, Australia & $(2.35 \pm 0.24) \times 10^{6}$ \\
\hline & MSHR668 & Clinical isolation, Australia & $10 \pm 1.66$ \\
\hline & E8 & Soil, Thailand & $(2.50 \pm 0.20) \times 10^{4}$ \\
\hline & $\mathrm{E} 412$ & Soil, Thailand & $(1.35 \pm 0.11) \times 10^{6}$ \\
\hline & MSHR491 & Water, Australia & $(5.00 \pm 0.44) \times 10^{5}$ \\
\hline \multirow[t]{6}{*}{ B.thailandensis } & D1 & Soil, Thailand & - \\
\hline & E28 & Soil, Thailand & - \\
\hline & E36 & Soil, Thailand & - \\
\hline & E68 & Soil, Thailand & - \\
\hline & E70 & Soil, Thailand & - \\
\hline & E94 & Soil, Thailand & - \\
\hline B. multivorans & LMG 16660 & Clinical isolation, UK & - \\
\hline B. ubonensis & DMST 866 & Soil, Thailand & - \\
\hline B. vietnamensis & LMG 6999 & Clinical isolation, Vietnam & - \\
\hline B. cepacia & ATCC 25416 & - & - \\
\hline P. aeruginosa & ATCC 27853 & - & - \\
\hline E. coli & ATCC 25922 & - & - \\
\hline
\end{tabular}

B. pseudomallei $\mathrm{K} 96243$ was used to propagate the phages and the stock was used to infect the other strains. The stock gave $2.90 \times 10^{7}$ pfu/ml on $\mathrm{K} 96243$ and the titre on the other strains is given in the table.Value represent the mean pfu/ml \pm S.E.M of triplicates, -, no plaque formation

determined using plaque assays. These data showed that the eclipse, latent period and burst size of $\Phi$ Bp-AMP1 on B. pseudomallei $\mathrm{K} 96243$ at $37^{\circ} \mathrm{C}$ were $40 \mathrm{~min}, 60$ min and $158 \pm 54$, respectively (Figure $2 \mathrm{~A}$ ). By comparison, the latent times of ФBp-AMP1 was longer and burst size was smaller than the recently described $B$. pseudomallei phage ST79 which had a latent period of $15 \mathrm{~min}$, and a burst size of 304 [10]. Although there appears to be a population of cells that are resistant to ФB-AMP1, this reflects the low titre of phages added to the culture. Bacteria from this culture were isolated and were still susceptible to phage infection and when higher MOI's were used in infection experiments total lysis was observed.

To investigate the thermal stability of the bacteriophages, a $10^{7} \mathrm{pfu} / \mathrm{ml}$ phage stock was incubated at $50^{\circ} \mathrm{C}$ and $60^{\circ} \mathrm{C}$ for 0,8 and $24 \mathrm{~h}$. These temperatures are significantly higher than the ambient temperature of rice fields in Thailand. At intervals, the bacteriophage stock was titred. Figure $2 \mathrm{~B}$ showed that $Ф \mathrm{Bp}-\mathrm{AMP} 1$ was stable for at least $8 \mathrm{~h}$ at $50^{\circ} \mathrm{C}$ but reduced from $10^{7} \mathrm{pfu} / \mathrm{ml}$ to $10^{4} \mathrm{pfu} / \mathrm{ml}$ after a further period of incubation from $8 \mathrm{~h}$ to $24 \mathrm{~h}$. However, no bacteriophages were detected after $1 \mathrm{~h}$ incubation at $60^{\circ} \mathrm{C}$ (data not shown). This data indicates that $\Phi B \mathrm{p}-\mathrm{AMP} 1$ may be useful even in high temperature environments. The loss of phage viability at $60^{\circ}$
$\mathrm{C}$ is a common observation, as seen for example in bacteriophages which infect Lactobacillus delbrueckii [13].

To obtain molecular data on this phage, we initially tried to amplify the DNA polymerase gene using designed primers from a subset of viruses belonging to the Podoviridae [14]. This was not successful probably due to a lack of sequence identity with known phages; we therefore randomly sequenced fragments of phage DNA. To do this, DNA was restricted using $\operatorname{Taq}^{\alpha} \mathrm{I}$ and $B s t \mathrm{BI}$ and cloned into the plasmid pBluescript (Stratagene, La Jolla, CA, USA). Colonies were screened to identify those that contained suitable fragment sizes. A PsiBLAST (NCBI) search from a sequenced region identified a gene (EMBL:FR850500) which had a homologue with an ORF coding for a phage tail tubular protein $B$ (TTPB) from a temperate B. thailandensis phage (GeneBank:ZP02468145.1). Fortuitously, this gene had been used as a phylogenetic marker in previous studies [15]. Therefore, a phylogenetic analysis was performed at the amino acid level using Molecular Evolutionary Genetics Analysis (MEGA) package version 4.1 (Beta) [16,17].

The tree in Figure 3 shows the results from a Neighbor joining analysis which was performed using a maximum composite likelihood model and a bootstrap analysis with 1, 000 replicates with bacteriophage $\mathrm{T} 7$ as an outgroup. The tree shows that ФBp-AMP1 is clearly 


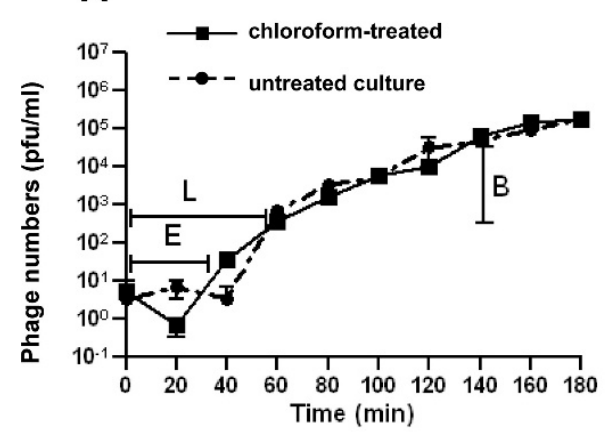

B

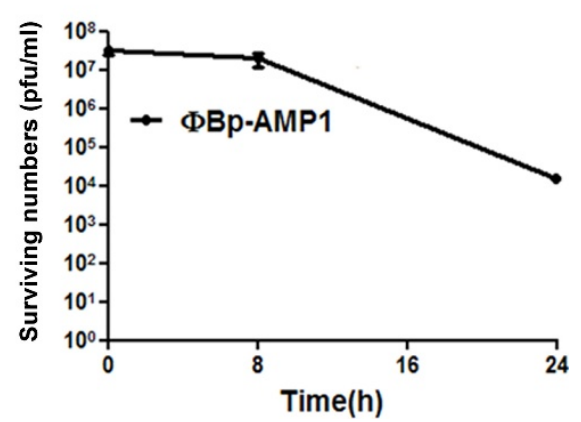

Figure 2 Growth curve and thermal stability of ФBp-AMP1. (A) One step growth curve of ФBp-AMP1 on B. pseudomallei strain K96243. Phage number $(\mathrm{pfu} / \mathrm{ml})$ in chloroform-treated $(\mathbb{\nabla})$ and the untreated culture $(\bullet)$; $E$, eclipse period; $L$, latent period and B, burst size. (B) Thermal stability of $\triangle \mathrm{Bp}-\mathrm{AMP} 1$ at $50^{\circ} \mathrm{C}$. Values are the means of three independent experiments

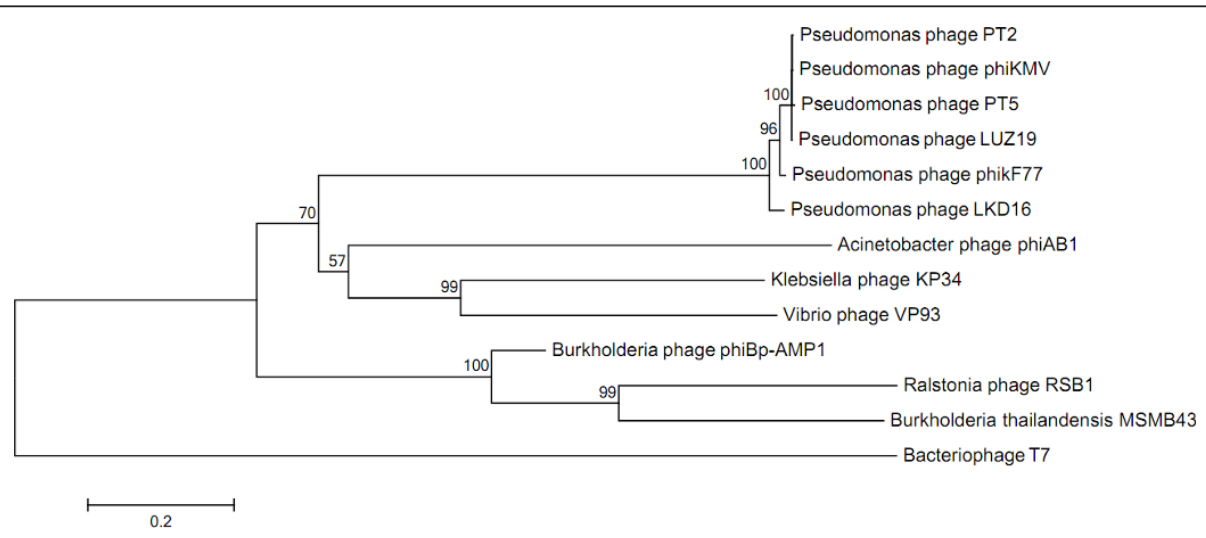

Figure 3 Phylogenetic tree of $\Phi$ Bp-AMP1 tail tubular protein B (TTPB) by the neighbour-joining method. Branch lengths are indicated below the branches. Bootstrap values are indicated at the nodes. The scale bar represents the proportion of amino acid compared.

separated from known phages but is most closely related to the B. thailandensis MSMB43 prophage and the T7like Ralstonia phage RSB1 (supported by a boots trap value of $100 \%$ ). This is logical because Ralstonia is closely related to soil-born Burkholderia species [18]. Interestingly, there is no clear relationship between $\Phi$ BpAMP1 and the characterised Pseudomonas phages. Analyses were also done using Parsimony and Maximum likelihood and all showed a similar tree topology.

In conclusion, we report the isolation of a podovirus which infects $B$. pseudomallei. The broad host-range and thermal stability of this phage suggests that it may have promise as a therapeutic agent. Further research is underway in our laboratories to characterise the genome of this bacteriophage and to establish its potential application for B. pseudomallei treatment.

\section{Acknowledgements}

This work was supported by a Wellcome Trust, UK (Grant number 092638/Z/ 10/Z) to MRJC, EEG and SK. We thank the students from the Department of
Medical Technology, Rangsit University for their assistances on soil sample collection, and the Wellcome Trust-Mahidol, University Oxford and Dr. H. Schweizer for providing some of the Burkholderia strains. SK is supported by "Chalermphrakiat" Grant, Faculty of Medicine Siriraj Hospital, Mahidol University. JG is supported by Rangsit University.

\section{Author details}

'Department of Immunology, Faculty of Medicine Siriraj Hospital, Mahidol University, Bangkok 10700, Thailand. ${ }^{2}$ Faculty of Medical Technology, Rangsit University, Pathumthani 12000, Thailand. ${ }^{3}$ Department of Infection, Immunity and Inflammation, Leicester Medical School, University of Leicester, Leicester LE1 9HN, UK.

\section{Authors' contributions}

$J G, K K$ and NI were responsible for soil samples collection. JG performed the phage biological characterisation, data analysis and drafted the manuscript. KK participated in the co-ordination of the study in Thailand. EEG, MRJC, and SK designed the study and interpreted the data. JS and ED carried out cloning, sequencing and phylogenetic analysis. SK and MRJC critically revised the manuscript. All authors have read and approved final manuscript.

\section{Competing interests}

The authors declare that they have no competing interests.

Received: 12 May 2011 Accepted: 26 July 2011 Published: 26 July 2011 
1. Dance DA: Melioidosis: the trip of the ice berg. Clin Microbiol Rev 1991, 4:52-60.

2. Wuthiekanun V, Smith MD, White NJ: Survival of Burkholderia pseudomallei in the absence of nutrients. Trans R Soc Trop Med Hyg 1995, 89:491.

3. Cheng AC, Currie BJ: Melioidosis: epidemiology, pathophysiology, and management. Clin Microbiol Rev 2005, 18:383-416.

4. Clokie MRJ, Millard AD, Leterov AV, Heaphy S: Phages in nature. Bacteriophage 2011, 1:31-45.

5. Gorski A, Miedzybrodzki R, Borysowski J, Weber-Dabrowska B, Lobocka M, Fortuna W, Letkiewicz S, Zimecki M, Filby G: Bacteriophage therapy for the treatment of infections. Curr Opin Investig Drugs 2009, 10:766-774.

6. Kutter E, De Vos D, Gvasalia G, Alavidze Z, Gogokhia L, Kuhl S, Abedon ST: Phage therapy in clinical practice: treatment of human infections. Curr Pharm Biotechnol 2010, 11:69-86.

7. Sariya L, Prempracha N, Keelapan P, Chittasophon N: Bacteriophage isolated from Burkholderia pseudomallei Causes phenotypic changes in Burkholderia thailandensis. ScienceAsia 2006, 32:83-91.

8. Ronning CM, Losada L, Brinkac L, Inman J, Ulrich RL, Schell M, Nierman WC, DeShazer D: Genetic and phenotypic diversity in Burkholderia: contributions by prophage and phage-like elements. BMC Microbio/ 2010, 10:202.

9. DeShazer D: Genomic diversity of Burkholderia pseudomallei clinical isolates: subtractive hybridization reveals a Burkholderia mallei-specific prophage in B. pseudomallei 1026b. J Bacteriol 2004, 186:3938-3950.

10. Yordpratum U, Tattawasart U, Wongratanacheewin S, Sermswan RW: Novel lytic bacteriophages from soil that lyse Burkholderia pseudomallei. FEMS Microbiol Lett 2010, 314:81-88.

11. Lingohr $E$, Frost $F$, Johnson RP: Determination of bacteriophage genome size by pulsed-field gel electrophoresis. In Bacteriophages: Methods and Protocols. Volume 2. Edited by: Clokie MRJ, Kropinski AM. Humana Press; 2009:19-25.

12. Pajunen M, Kiljunen S, Skurnik M: Bacteriophage phiYeO3-12, specific for Yersinia enterocolitica serotype 0:3, is related to coliphages T3 and T7. Bacteriol 2000, 182:5114-5120

13. Quiberoni A, Guglielmotti DM, Reinheimer JA: Inactivation of Lactobacillus delbrueckii bacteriophages by heat and biocides. Int J Food Microbiol 2003, 84:51-62.

14. Labonte JM, Reid KE, Suttle CA: Phylogenetic analysis indicates evolutionary diversity and environmental segregation of marine podovirus DNA polymerase gene sequences. Appl Environ Microbiol 2009, 75:3634-3640.

15. Chai $Y$, Xiong H, Ma X, Cheng L, Huang G, Zhang ZR: Molecular characterization, structural analysis and determination of host range of a novel bacteriophage LSB-1. Virol J 7:255.

16. Kumar S, Nei M, Dudley J, Tamura K: MEGA: a biologist-centric software for evolutionary analysis of DNA and protein sequences. Brief Bioinform 2008, 9:299-306

17. Tamura K, Dudley J, Nei M, Kumar S: MEGA4: Molecular evolutionary genetics analysis (MEGA) software version 4.0. Mol Biol Evol 2007, 24:1596-1599.

18. Yabuuchi E, Kosako Y, Oyaizu H, Yano I, Hotta H, Hashimoto Y, Ezaki T, Arakawa M: Proposal of Burkholderia gen. nov. and transfer of seven species of the genus Pseudomonas homology group II to the new genus, with the type species Burkholderia cepacia (Palleroni and Holmes 1981) comb. nov. Microbiol Immunol 1992, 36:1251-1275.

doi:10.1186/1743-422X-8-366

Cite this article as: Gatedee et al:: Isolation and characterization of a novel podovirus which infects burkholderia pseudomallei. Virology Journal $20118: 366$

\section{Submit your next manuscript to BioMed Central and take full advantage of:}

- Convenient online submission

- Thorough peer review

- No space constraints or color figure charges

- Immediate publication on acceptance

- Inclusion in PubMed, CAS, Scopus and Google Scholar

- Research which is freely available for redistribution

Submit your manuscript at www.biomedcentral.com/submit
C) Biomed Central 